\title{
The use of disjunct eddy sampling methods for the determination of ecosystem level fluxes of trace gases
}

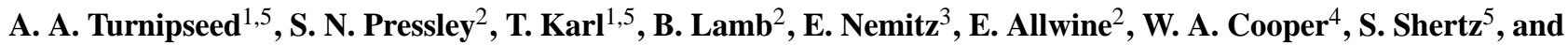 \\ A. B. Guenther ${ }^{1,5}$ \\ ${ }^{1}$ Atmospheric Chemistry Division, National Center for Atmospheric Research, P.O. Box 3000 Boulder, CO 80307, USA \\ ${ }^{2}$ Dept. of Civil and Environmental Engineering, Washington State University, Pullman, WA, USA \\ ${ }^{3}$ Center for Ecology and Hydrology (CEH), Edinburgh, UK \\ ${ }^{4}$ Earth Observing Laboratory, National Center for Atmospheric Research, P.O. Box 3000 Boulder, CO 80307, USA \\ ${ }^{5}$ The Institute for Integrative and Multidisciplinary Earth Studies (TIIMES), National Center for Atmospheric Research, P.O. \\ Box 3000 Boulder, CO 80307, USA
}

Received: 19 May 2008 - Published in Atmos. Chem. Phys. Discuss.: 15 July 2008

Revised: 24 November 2008 - Accepted: 13 January 2009 - Published: 9 February 2009

\begin{abstract}
The concept of disjunct eddy sampling (DES) for use in measuring ecosystem-level micrometeorological fluxes is re-examined. The governing equations are discussed as well as other practical considerations and guidelines concerning this sampling method as it is applied to either the disjunct eddy covariance (DEC) or disjunct eddy accumulation (DEA) techniques. A disjunct eddy sampling system was constructed that could either be combined with relatively slow sensors (response time of 2 to $40 \mathrm{~s}$ ) to measure fluxes using DEC, or could also be used to accumulate samples in stable reservoirs for later laboratory analysis (DEA technique). Both the DEC and DEA modes of this sampler were tested against conventional eddy covariance (EC) for fluxes of either $\mathrm{CO}_{2}$ (DEC) or isoprene (DEA). Good agreement in both modes was observed relative to the EC systems. However, the uncertainty in a single DEA flux measurement was considerable $(\sim 40 \%)$ due to both the reduced statistical sampling and the analytical precision of the concentration difference measurements. We have also re-investigated the effects of nonzero mean vertical wind velocity on accumulation techniques as it relates to our DEA measurements. Despite the higher uncertainty, disjunct eddy sampling can provide an alternative technique to eddy covariance for determining ecosystem-level fluxes for species where fast sensors do not currently exist.
\end{abstract}

Correspondence to: A. Turnipseed (turnip@ucar.edu)

\section{Introduction}

Eddy covariance (EC) has gained acceptance as one of the most direct means of measuring ecosystem-level fluxes. It relies on the ability to measure concentration and wind fluctuations concurrently to obtain the covariance between these two measures. However, in order to fully capture all of the atmospheric motions that can contribute to the measured flux; measurements must be made rapidly (usually $\geq 10 \mathrm{~Hz}$ ). Although an increasing number of trace atmospheric species are being measured with the necessary speed and precision for eddy covariance, many more are limited by currently available sensors. Micrometeorological flux techniques that are compatible with slow sensors include the use of concentration gradients (Denmead, 1983) and Relaxed Eddy Accumulation (REA) (Businger and Oncley, 1990). However, gradients can be biased over tall canopies due to counter-gradient transport (Cellier and Brunet, 1992) and non-logarithmic profiles within the roughness sublayer. Gradients also often rely on similarity theory and the measurement of an EC flux and gradient of another species (e.g., the Bowen ratio technique, see Denmead, 1983; Fowler and Duyzer, 1989). REA relies on a coefficient which is often empirically derived from eddy covariance fluxes of another scalar and related to the desired species through similarity (Businger and Oncley, 1990; Pattey et al., 1993; Bowling et al., 1998). It is desirable to develop other micrometeorological methods that are compatible with slow sensors, but are not reliant on similarity assumptions and are applicable over a variety of surfaces and ecosystem types.

Published by Copernicus Publications on behalf of the European Geosciences Union. 


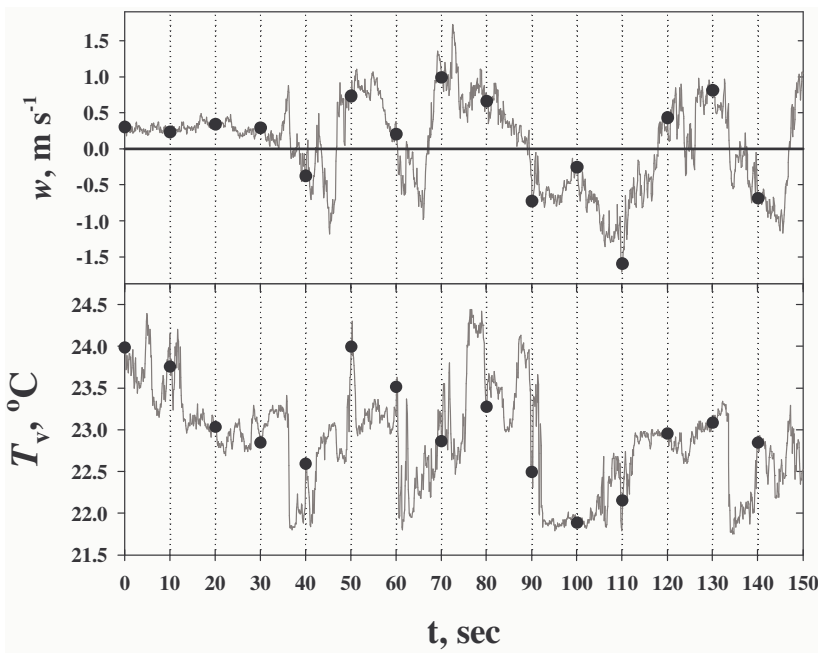

Fig. 1. Time series of vertical velocity and virtual sonic temperature illustrating the disjunct sampling method. Points indicate disjunctly-sampled points within the $10 \mathrm{~Hz}$ time series every $10 \mathrm{~s}$.

The concept of disjunct eddy sampling (DES) for the determination of fluxes was originally proposed in the 1970's (Haugen, 1978) as a means of collecting the minimum amount of data to determine the eddy covariance flux. It has been shown that as long as the sampling period is kept rapid $(<0.2 \mathrm{~s}$ for measuring heights $>2 \mathrm{~m})$ to capture the high frequency fluctuations, the covariance between vertical component of the wind velocity and a scalar from a non-biased, temporally discontinuous set of points can adequately describe the flux (Haugen, 1978, Lenschow et al., 1994). Disjunct eddy sampling is depicted in Figure 1, where a rapid measurement of both a scalar and the vertical velocity are measured every $10 \mathrm{~s}$. Lenschow et al. (1994) concluded that as long as the interval between samples is less than the integral time scale of the turbulence ( $\tau_{w}$, typically between 15 to $60 \mathrm{~s}$ over forests), there is (1) little or no flux loss and (2) only a small increase $(\leq 8 \%)$ in the statistical error variance. This allows for a longer sample analysis time (1 to $30 \mathrm{~s}$ ) required for some sensors. This form of eddy covariance, which we shall refer to as Disjunct Eddy Covariance (DEC), has been shown to provide reasonable flux measurements in past studies (Rinne et al., 2001; Warneke et al., 2002; Karl et al., 2002) and has been experimentally verified with direct EC measurements (Ammann et al., 2006; Rinne et al., 2008).

For some species, available sensors operate only at time scales $>30 \mathrm{~s}$. Eddy accumulation (EA), originally described by Desjardin (1977), and consists of partitioning air into two reservoirs (updrafts and downdrafts) based on the magnitude and direction of the vertical velocity. The species' densities (or masses) in the updraft and downdraft reservoirs could then be used to determine the flux. This method, in effect, substitutes fast mass (or flow) control for the capability of fast measurements (Lenschow, 1995). However, in terms of practical implementation, fast mass control is extremely difficult to accomplish. The discontinuous nature of DES allows for tractable mass flow control for each sample and allows eddy accumulation to be a viable flux method (Disjunct Eddy Accumulation or DEA, Rinne et al., 2000). This provides a powerful alternative to both gradients or REA, as this is a direct flux technique (not reliant on similarity assumptions), can be used over a variety of canopies, and provides a method in which samples can be stored, transported and then analyzed by a variety of slower methods. DEA has been implemented previously (Rinne et al., 2000, Rinne et al., 2002) and tended to give measured fluxes of reasonable magnitude that responded to environmental drivers in expected ways. However, this method has not been directly validated against other flux methods (such as eddy covariance) to our knowledge.

In this paper, we re-visit the topic of disjunct eddy sampling as it pertains both to DEC and DEA for tower-based flux measurements, discussing advantages and limitations of the methods. Secondly we describe a sampler designed for both DEC and DEA measurements, depending on the species of interest and the sensor available. Furthermore, we show direct evaluation of this sampler versus eddy covariance measurements in both operating modes.

\section{Disjunct sampling: theory and practice}

\subsection{Disjunct eddy covariance (DEC)}

The turbulent flux of a scalar, $c$, from continuously-sampled data (i.e., EC sampling) is computed as the covariance between scalar density, $c$, and the vertical velocity component of the wind, $w$ (assuming a negligible mean vertical velocity):

$$
F_{c}=\overline{w^{\prime} c^{\prime}}=\frac{1}{T_{\mathrm{avg}}} \int_{0}^{T_{\mathrm{avg}}} w^{\prime}(t) c^{\prime}(t) d t
$$

where $w^{\prime}$ and $c^{\prime}$ are fluctuations from the mean of the vertical velocity $(\bar{w})$ and the scalar density $(\bar{c})$, respectively, and $T_{\text {avg }}$ is the flux averaging period (typically $\sim 15$ to $60 \mathrm{~min}$.). For a disjunctly sampled time series, the flux can be estimated as the covariance of the subset of points (Rinne et al., 2000):

$F_{c}=\left\langle w^{\prime} c^{\prime}\right\rangle_{\mathrm{disj}}=\frac{1}{N} \sum_{i=1}^{N} w_{i}^{\prime} c_{i}^{\prime}$

where $N$ is the total number of disjunctly sampled points. Assumptions concerning temporal stationarity and adequate homogeneous fetch (Foken and Wichura, 1996) apply to both EC and DEC. Corrections for density changes (Webb et al., 1980) and coordinate rotation schemes (Wilczak et al., 2001; Kaimal and Finnigan, 1994) can be applied equally to disjunctly sampled time series. A major disadvantage of DEC 
is that spectral analysis is not possible with a discontinuous time series (Lenschow et al., 1994); thus, frequencydependent corrections cannot be applied.

\subsection{Disjunct eddy accumulation (DEA)}

The premise of eddy accumulation (EA) is that air is partitioned into updraft and downdraft reservoirs over some averaging period based on the sign of the vertical velocity and proportional to its magnitude. For continuous sampling, the total flux can be related to the concentrations in the updraft and downdraft reservoirs as (Desjardin, 1977; Hicks and McMillen, 1984):

$\overline{w c}=\frac{1}{T_{\mathrm{avg}}} \int_{0}^{T_{\mathrm{avg}}}\left(\delta^{+} c w+\delta^{-} c w\right) d t=\bar{w} \bar{c}+\overline{w^{\prime} c^{\prime}}$

where $\delta^{+}=1$ when $w>\bar{w}$ and 0 when $w<\bar{w}$. Conversely, $\delta^{-}=0$ when $w>\bar{w}$ and 1 when $w<\bar{w}$. Since air is partitioned based on current wind data, it is difficult to remove any offsets in the vertical wind velocity; therefore, mean components to the flux cannot be neglected (but note that when $\bar{w} \approx 0$, the total flux equals the turbulent flux, $w^{\prime} c^{\prime}$ ). For disjunctly sampled points, the turbulent flux can be shown to be:

$F_{c}=\left\langle w^{\prime} c^{\prime}\right\rangle_{\text {disj }}=\frac{1}{N} \sum_{i=1}^{N}\left(\delta^{+} w_{i} c_{i}+\delta^{-} w_{i} c_{i}\right)-\bar{w}_{\text {disj }} \bar{c}_{\text {disj }}$

where $\bar{w}_{\text {disj }}$ and $\bar{c}_{\text {disj }}$ are the mean vertical velocity and scalar density of the disjunctly sampled points. This equation can be used directly to ascertain the flux, but, as discussed by Businger and Oncley (1990), each of these terms can be larger than the flux itself, so very accurate measurements are necessary to reduce the uncertainty. It is more practical to express this equation in terms of a concentration difference multiplied by a term related to the vertical velocity. To simplify Eq. (4), we note that the volume $\left(V_{i}^{+}\right.$for updrafts and $V_{i}^{-}$for downdrafts) from each disjunctly isolated air sample to be stored must be dispensed proportional to $w_{i}$ :

$V_{i}^{ \pm}=k\left|w_{i}\right| \delta^{ \pm}$

where $k$ is a constant relating the sampling flow rate and/or dispense time to $w$. The total volume in a particular reservoir over the entire flux averaging period is then:

$V^{ \pm}=k \sum_{i=1}^{N}\left|w_{i}\right| \delta^{ \pm}$

and the mass of the scalar collected in each reservoir is:

$m^{ \pm}=k \sum_{i=1}^{N} c_{i}\left|w_{i}\right| \delta^{ \pm}$
Substitution into Eq. (4) gives:

$\left\langle w^{\prime} c^{\prime}\right\rangle_{\mathrm{disj}}=\frac{1}{k N}\left(m^{+}-m^{-}\right)-\bar{w}_{\mathrm{disj}} \bar{c}_{\mathrm{disj}}$,

similar to the form reported for continuous EA (Hicks and McMillen, 1984).

When $\bar{w}_{\text {disj }} \approx 0$ (or $\sum_{i=1}^{N}\left|w_{i}\right| \delta^{+}=\sum_{i=1}^{N}\left|w_{i}\right| \delta^{-}$), Eq. (6) indicates equal volumes will be collected in the updraft and downdraft containers, $V^{+}=V^{-}=V^{ \pm}$(with $V_{\text {tot }}=$ $\left.V^{+}+V^{-}\right)$. This volume can be related to $w$ via:

$V^{ \pm}=V_{\mathrm{tot}} / 2=\frac{N k}{2} \frac{\sum_{i=1}^{N}\left|w_{i}\right|}{N}=\frac{N k \overline{\left|w_{\mathrm{disj}}\right|}}{2}$

Dividing through by $V^{ \pm}$to convert mass to density $\left(c^{+}=\right.$ $m^{+} / V^{ \pm}$and $c^{-}=m^{-} / V^{ \pm}$) and substitution using Eq. (6) gives:

$F_{c}=\left\langle w^{\prime} c^{\prime}\right\rangle_{\mathrm{disj}}=\frac{V^{ \pm}}{k N}\left(c^{+}-c^{-}\right)=\frac{\overline{\left|w_{\mathrm{disj}}\right|}}{2}\left(c^{+}-c^{-}\right)$.

Equation (10) provides a simple equation to derive the flux under ideal conditions.

When $\bar{w}_{\text {disj }} \neq 0$, unequal volumes in the updraft and downdraft reservoirs are collected. Following Hicks and McMillen (1984), we assume:

$\Delta V=V^{+}-V^{-}=2 f V_{\text {tot }}$ with $f=\left(\frac{V^{+}}{V_{\text {tot }}}-\frac{1}{2}\right)$

and "correct" the mass in each accumulated reservoir relative to the ideal case $\left(m_{V}\right)$ above:

$m^{+}=m_{V}^{+}+\frac{\Delta V}{2} c^{+}=m_{V}^{+}+V_{\text {tot }} f c^{+}$,
$m^{-}=m_{V}^{-}-\frac{\Delta V}{2} c^{-}=m_{V}^{-}-V_{\text {tot }} f c^{-}$.

Substituting $V_{\text {tot }}=N k \overline{\left|w_{\text {disj }}\right|}$ and inserting into Eq. (8) yields:

$$
\begin{aligned}
\left\langle w^{\prime} c^{\prime}\right\rangle_{\mathrm{disj}}=\frac{1}{k N}\left(m_{V}^{+}-m_{V}^{-}\right) & +f \overline{\left|w_{\mathrm{disj}}\right|}\left(c^{+}+c^{-}\right) \\
& -\bar{w}_{\mathrm{disj}} \bar{c}_{\mathrm{disj}} .
\end{aligned}
$$

$\overline{\left|w_{\text {disj }}\right|}$ and $\bar{w}_{\text {disj }}$ can then be related via:

$$
\begin{aligned}
\bar{w}_{\text {disj }}=\frac{1}{N} \sum_{i=1}^{N}\left|w_{i}\right|\left(\delta^{+}-\delta^{-}\right) & =\frac{1}{k N}\left(V^{+}-V^{-}\right) \\
& =\frac{2 V_{\text {tot }} f}{k N}=2 f \overline{\left|w_{\text {disj }}\right|}
\end{aligned}
$$



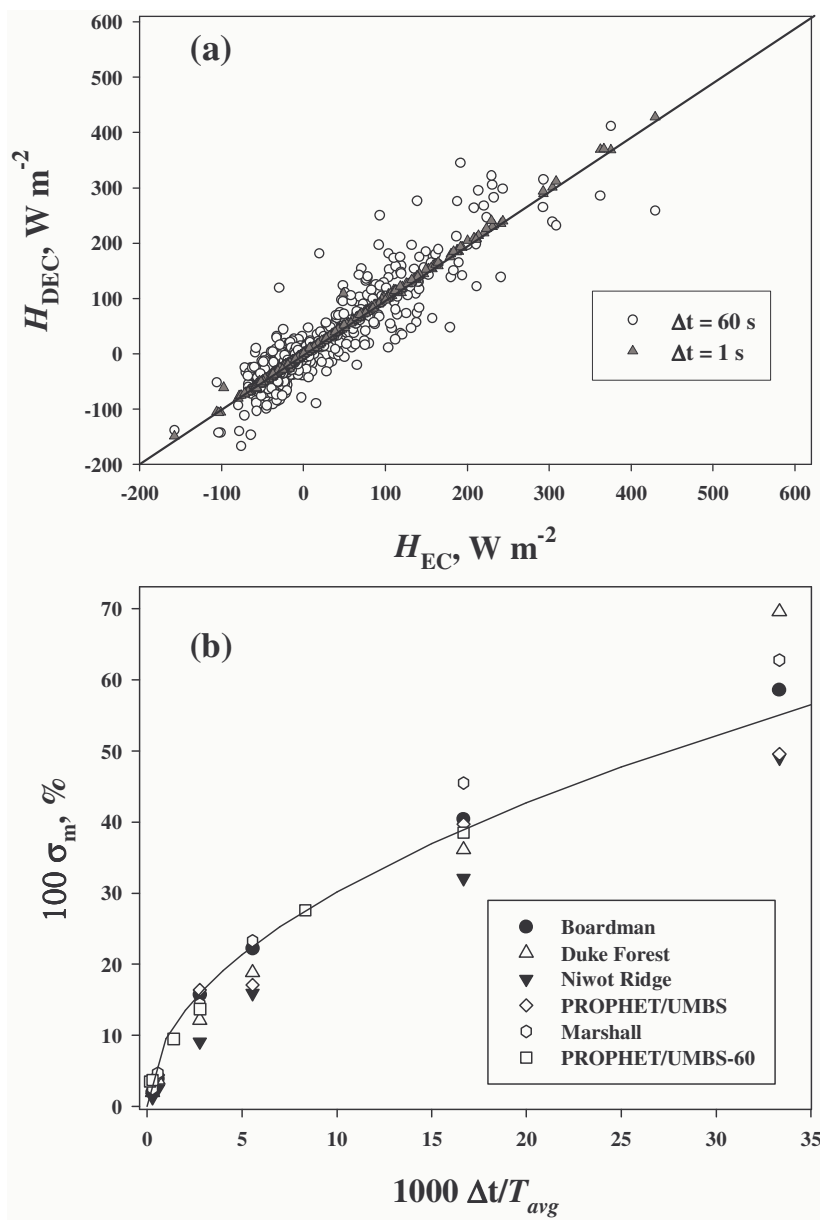

Fig. 2. (a) Plots of sensible heat fluxes derived by the covariance from disjunctly sampled time series $\left(H_{\mathrm{DEC}}\right.$, with $\Delta \mathrm{t}=1$ or $60 \mathrm{~s}$, $T_{\text {avg }}=1800 \mathrm{~s}$ ) compared to those using the full $10-\mathrm{Hz}$ time series $\left(H_{E C}\right.$, conventional eddy covariance). Data was taken from 10 days of measurements from the UMBS/PROPHET site (b) Plot of the standard deviation of the slope $\left(\sigma_{m}\right)$ vs. $\Delta \mathrm{t} / T_{\text {avg }}$ (see text for further explanation). All measurements had $T_{\mathrm{avg}}=1800 \mathrm{~s}$ except for those denoted as UMBS/PROPHET - 60, which used a $60 \mathrm{~min}$. averaging time. The line drawn is a fit to Eq. (17).

so that Eq. (15) becomes:

$\left\langle w^{\prime} c^{\prime}\right\rangle_{\mathrm{disj}}=\frac{1}{k N}\left(m_{V}^{+}-m_{V}^{-}\right)+\bar{w}_{\mathrm{disj}}\left(\frac{\left(c^{+}+c^{-}\right)}{2}-\bar{c}_{\mathrm{disj}}\right)$

or completely in terms of densities:

$F_{c}=\left\langle w^{\prime} c^{\prime}\right\rangle=\frac{\overline{\left|w_{\mathrm{dijj}}\right|}}{2}\left(c_{V}^{+}-c_{V}^{-}\right)+\bar{w}_{\mathrm{disj}}\left(\frac{\left(c^{+}+c^{-}\right)}{2}-\bar{c}_{\mathrm{disj}}\right)$.

The first term on the right hand side is essentially that derived in Eq. (10) if ideally sampled $\left(\bar{w}_{\text {disj }}=0, V^{+}=V^{-}\right)$. We then note that the difference in the last terms of Eq. (16) is between the measured mean density $(\bar{c})$ from the two reservoirs (weighted by the appropriate volumes) and an unweighted $\left(\left(c^{+}+c^{-}\right) / 2\right)$ mean density. This difference is often small (we will show experimental proof of this later), and results in only a small overestimate of the flux $(<4 \%)$.

2.3 Statistical error from disjunctly sampling and selection of $\Delta \mathrm{t}$

Figure 2a shows a comparison of heat fluxes calculated by both EC and DEC (from disjunctly sampling $10 \mathrm{~Hz}$ time series). Two different intervals $(\Delta t)$ between disjunctly sampled points were used $(1 \mathrm{~s}$ and $60 \mathrm{~s})$. Note that as $\Delta \mathrm{t}$ becomes larger, there is an increase in the spread of the data, but the overall average flux measured remains the same (i.e., the linear regression slope $=1$ ). This is indicative of the increase in statistical sampling error as fewer points are used to determine the covariance. We computed the standard deviation of the regression slope $\left(\sigma_{m}\right)$ from plots of disjunctly sampled heat fluxes vs. EC heat fluxes (Fig. 2a). Figure $2 b$ then shows how $\sigma_{m}$ changes as a function of $\Delta \mathrm{t} / T_{\mathrm{avg}}$. Data from 5 sites (described in Table 1 and Sect. 3.1) are shown that include deciduous (UMBS/PROPHET and Boardman), and coniferous (Niwot Ridge, Duke) forests as well as short-grass prairie (Marshall). All of these sites tend to show a similar pattern. These data were fit to the expression:

$\sigma_{m}(\%)=9.55\left(\frac{1000 \Delta t}{T_{\mathrm{avg}}}\right)^{0.5}$

which can be used as a empirically-derived guideline for estimating the additional error imposed by disjunct sampling relative to continuous sampling without the need for specific turbulence data. The square-root dependence is consistent with Lenschow et al. (1994), who report a linear dependence of the overall error variance $\left(\sigma^{2}\right)$ of a disjunctly sampled flux measurement with $\Delta \mathrm{t} / T_{\text {avg }}$. To determine the overall estimated error in a given disjunctly-measured flux measurement, the equations presented in Lenschow et al. (1994), should be consulted.

Decreasing the statistical sampling error requires either small $\Delta \mathrm{t}$ or larger flux averaging times, $T_{\text {avg. Non- }}$ stationarities in the wind flow and environmental variables tend to limit the length of flux averaging periods to about $1 \mathrm{~h}$ (Foken and Wichura, 1996). For DEC, the lower limit of $\Delta t$ is typically limited by the time required to flush any connecting sampling lines and the analytical sensor with sample gas and provide adequate signal integration time for the necessary measurement precision.

For DEA, it may still be necessary to flush any sampling lines, but an additional consideration is that one must be able to dispense volume over the range of $w_{i}^{\prime}$ values encountered within a flux period. Hicks and McMillen (1984) recommended that the dynamic range of a sampling system for eddy accumulation be able to span at least two orders of magnitude with a minimum resolution of $\sim 10 \mathrm{~cm} \mathrm{~s}^{-1}$. If (as will be described in this study) we dispense volume to a given 
Table 1. Description of measuring sites used in this study.

\begin{tabular}{lllll}
\hline Sites & Niwot Ridge & UMBS/PROPHET & Boardman & Duke Forest \\
\hline Ecosystem & Coniferous forest & Deciduous mixed forest & Deciduous plantation & Conifer plantation \\
Longitude-Latitude & $40^{\circ} 1^{\prime} 58.4^{\prime \prime} \mathrm{N} 105^{\circ} 32^{\prime} 47.1^{\prime \prime} \mathrm{W}$ & $45^{\circ} 33^{\prime} 35.4^{\prime \prime} \mathrm{N} 84^{\circ} 42^{\prime} 49.7^{\prime \prime} \mathrm{W}$ & $45^{\circ} 43.8^{\prime} \mathrm{N} 119^{\circ} 33.2^{\prime} \mathrm{W}$ & $35^{\circ} 58^{\prime} 41.4^{\prime \prime} \mathrm{N} 79^{\circ} 5^{\prime} 39.1^{\prime \prime} \mathrm{W}$ \\
Canopy Height $\left(\mathrm{h}_{c}\right)$ & $11.5 \mathrm{~m}$ & $23 \mathrm{~m}$ & $9 \mathrm{~m}$ & $16 \mathrm{~m}$ \\
LAI $\left(\mathrm{m}^{2} \mathrm{~m}^{-2}\right)$ & 4.1 & 3.7 & $\mathrm{~N} / \mathrm{A}$ & $0.25 \mathrm{~m}$ \\
Measurement year & 2003 & 2005 & 2004 & 3.2 \\
Measurement height $(\mathrm{z}, \mathrm{m})$ & 22 & 34 & 24 & 2003 \\
References & $\mathrm{a}$ & $\mathrm{b}$ & $\mathrm{c}$ & 26 \\
& & & $\mathrm{~d}$ & 2.4 \\
\end{tabular}

a - Turnipseed et al. (2002); Monson et al. (2002): http://public.ornl.gov/ameriflux/Site_Info/siteInfo.cfm?KEYID=us.niwot_ridge.01

b - Schmid et al. (2003); Pressley et al. (2005): http://public.ornl.gov/ameriflux/Site_Info/siteInfo.cfm?KEYID=us.umbs.01

c - Unpublished data

d - Katul et al. (1999): http://public.ornl.gov/ameriflux/Site_Info/siteInfo.cfm?KEYID=us.duke_loblolly.01

reservoir with a constant flow rate and vary the dispense time $\left(\tau_{d}\right)$ with $w_{i}$ (thereby $V_{i} \propto w_{i}$ ), the $\tau_{d}$ needed to meet the minimum criteria would be $10 \mathrm{~s}$ (assuming that we can control valves to the nearest $0.1 \mathrm{~s}$ ).

\subsection{Measurement precision}

Ritter et al. (1990), have discussed the error arising from instrumental white noise relative to the statistical error for eddy covariance fluxes. They show that for instrumental noise contribution to be less than the statistical uncertainty, the instrumental measurement precision $\left(\sigma_{p}\right)$ must be:

$\sigma_{p} \leq 2 \sigma_{c}\left(\frac{\tau_{w}}{\Delta t}\right)^{0.5}$

where $\sigma_{c}$ is the actual atmospheric concentration variability. This also holds for disjunct sampling, so that as $\Delta \mathrm{t}$ is increased, a more precise measurement is required.

For DEA, rearrangement of Eq. (10) yields an analogous expression as that given by Hicks and McMillen (1984) for EA:

$$
\frac{c^{+}-c^{-}}{\bar{c}}=\frac{\Delta C}{\bar{c}}=\frac{2.5 V_{c}}{\sigma_{w, d}} .
$$

Here, $V_{c}=\left|F_{c}\right| / \bar{c}$ (tantamount to the commonly used deposition velocity for a depositing species - we use the absolute value to include both emission and deposition fluxes) and $0.8 \sigma_{w, d}=\overline{\left|w_{\text {disj }}\right|}$ (which assumes the disjunctly sampled vertical velocity time series is Gaussian, Hicks and McMillen, 1984). Table 2 shows several species for which typical values of $V_{c}$ are given and the instrumental precision necessary for the successful use of DEA. As seen in the table, instrumental precision becomes of paramount importance when $V_{c}<$ about $5 \mathrm{~mm} \mathrm{~s}^{-1}$.

\section{Experimental}

\subsection{Site descriptions}

Sonic anemometer data from 5 different sites were used in this study. A brief description of all of these sites is given in Table 1. Two of these sites (Niwot Ridge and UMBS/PROPHET) were used for testing our Disjunct Eddy Sampler in the present study. Initial DEC measurements of $\mathrm{CO}_{2}$ fluxes were conducted at the Niwot Ridge AmeriFlux site in Colorado in September of 2003. DEA measurements of isoprene fluxes were made at the University of Michigan Biological Station (UMBS) at the PROPHET (Program for Research on Oxidation, PHotochemistry, Emissions and Transport) tower site in northern Michigan during JulyAugust 2005. Both of these research sites are described in detail in other publications (Monson et al., 2002; Schmid et al., 2003; Carroll et al., 2001). It should also be noted that both of these sites belong to the AmeriFlux tower network and, thus, continuously measure a wide array of meteorological and environmental variables (wind speed/direction, light, temperature, relative humidity, etc.) and fluxes (sensible and latent heat, net ecosystem exchange).

The Niwot Ridge site lies in fairly complex topography (Turnipseed et al., 2003); however, past measurements have shown that surfaces fluxes can be reliably measured during a majority of time periods via the eddy covariance technique (Turnipseed et al., 2002). Furthermore, both the EC and DEC will be affected in a similar fashion from errors created by either horizontal or vertical advection.

The primarily-deciduous forest at the UMBS/PROPHET site is not as complicated topographically (maximum elevation change of $20 \mathrm{~m}$ over $1 \mathrm{~km}$ distance in any direction). However, it is complicated by the larger number of tree species present, only some of which emit isoprene. This leads to a more heterogeneous surface with respect to isoprene emission. Bigtooth aspen (Populus grandidentata Michx.), quaking aspen (P. tremuloides Michx.), and red oak 
Table 2. Examples of species and the necessary instrumental precision for use with Disjunct Eddy Accumulation.

\begin{tabular}{lllll}
\hline Species & Ecosystem & $\mathrm{V}_{c},{ }^{\mathrm{a}} \mathrm{mm} \mathrm{s}^{-1}$ & $\Delta \mathrm{C} / \mathrm{c}:{ }^{\mathrm{b}} \sigma_{w}=0.3 \mathrm{~m} \mathrm{~s}^{-1}$ & $\sigma_{w}=1.2 \mathrm{~m} \mathrm{~s}^{-1}$ \\
\hline Isoprene & Deciduous forest & $76-140$ & $63-117 \%$ & $16-29 \%$ \\
Monoterpenes & Deciduous forest & $66-280$ & $55-233 \%$ & $14-58 \%$ \\
Methanol & Deciduous forest & 23 & $19.1 \%$ & $4.8 \%$ \\
Acetone & Deciduous forest & $17-44$ & $14-37 \%$ & $3.5-9.2 \%$ \\
$\mathrm{HNO}_{3}$ & Deciduous forest & $20-60$ & $16-50 \%$ & $4.2-12 \%$ \\
$\mathrm{SO}_{2}$ & Deciduous forest & 10 & $8.3 \%$ & $2.1 \%$ \\
$\mathrm{O}_{3}$ & Conifer Forest & 7 & $5.8 \%$ & $1.5 \%$ \\
$\mathrm{CO}_{2}$ & Subalpine Conifer & 0.9 & $0.8 \%$ & $0.2 \%$ \\
$\mathrm{CH}_{4}$ & wetlands & 0.5 & $0.4 \%$ & $0.1 \%$ \\
$\mathrm{~N}_{2} \mathrm{O}$ & Grassland & 0.1 & $0.08 \%$ & $0.02 \%$ \\
\hline
\end{tabular}

a $V_{c}=\left|F_{c}\right| / \bar{c}$ at a reference height of $\sim 10 \mathrm{~m}$ above the canopy. $V_{c}$ values represent a range and are derived from data reported in: VOCs: Karl et al., (2004); Lamb et al. (1985). $\mathrm{HNO}_{3}$ : Meyers et al. (1989), $\mathrm{SO}_{2}$ and $\mathrm{O}_{3}$ : Finkelstein et al. (2000), $\mathrm{CO}_{2}$ : Monson et al. (2002) (Niwot Ridge), $\mathrm{CH}_{4}$ and $\mathrm{N}_{2} \mathrm{O}$ : Wesely et al. (1989).

b As $\Delta C / \bar{c}$ is a function of $\sigma_{w, d}$, (Eq. 19), two values of $\sigma_{w, d}$ are given to represent both calm and windy conditions.

(Quercus rubra L.) are the primary isoprene emitters and account for approximately $69 \%$ of the total biomass (Pressley et al., 2005) within a $1 \mathrm{~km}$ radius of the flux tower. Within close proximity of the tower, these species were dispersed fairly evenly over all wind sectors (Westberg et al., 2001).

\subsection{Eddy covariance measurements}

At the Niwot Ridge site, eddy covariance fluxes of $\mathrm{CO}_{2}$ were measured using a 3-dimensional sonic anemometer (CSAT3, Campbell Scientific) and a closed-path infrared gas analyzer (IRGA, Licor Li-6262) at a height of $21.5 \mathrm{~m}(\sim 10 \mathrm{~m}$ above the canopy). A detailed description of the system has been given previously (Monson et al., 2002, Turnipseed et al., 2003). DEC measurements were made at $\mathrm{z}=22 \mathrm{~m}$.

At UMBS/PROPHET, wind velocities were measured by a sonic anemometer (Applied Technologies, SATI-K) positioned at $\mathrm{z}=34 \mathrm{~m}$. Isoprene $\left(\mathrm{C}_{5} \mathrm{H}_{8}\right)$ was measured at 10 $\mathrm{Hz}$ using a Fast Isoprene Sensor (FIS, Hills Scientific, Inc.) which uses the chemi-luminescent reaction of reactive olefins with ozone as a detection method (Guenther and Hills, 1998). Since isoprene is by far the major reactive olefin that has been detected in the atmosphere at this site (Barket et al., 2001; Karl et al., 2003), there is little interference from other species. A full description of the instrument and calibration procedures can be found in Pressley et al. (2005).

Isoprene fluxes were also measured using the method of "virtual" disjunct eddy covariance ( $v$ DEC) with a protontransfer mass spectrometer (PTRMS, Ionicon). This method and instrumentation has been described in depth previously (Karl et al., 2001; Karl et al., 2002). Briefly, air flow is sampled continuously into the PTRMS where it is reacted with gas phase $\mathrm{H}_{3} \mathrm{O}^{+}$ions. Subsequent ion-molecule reaction products are mass filtered (quadrupole mass filter) and detected with an electronmultiplier. Isoprene was monitored from the reaction product at mass to charge ratio $(\mathrm{m} / \mathrm{z})$ of 69 formed via:

$\mathrm{C}_{5} \mathrm{H}_{8}+\mathrm{H}_{3} \mathrm{O}^{+} \rightarrow \mathrm{C}_{5} \mathrm{H}_{9}^{+}+\mathrm{H}_{2} \mathrm{O}$

In the "virtual" DEC mode, a particular mass to charge ratio $(\mathrm{m} / \mathrm{z})$ is only monitored for $\sim 0.1 \mathrm{~s}$ each $7.9 \mathrm{~s}$ (i.e., this is a DEC measurement with a $\Delta \mathrm{t}=7.9 \mathrm{~s}$ ). This allows for fluxes of many different compounds (different $\mathrm{m} / \mathrm{z}$ ) to be measured with a single instrument.

\subsection{Disjunct Eddy Sampler}

The Disjunct Eddy Sampler (DES) is a sampling system designed to capture a sample of gas corresponding to a small time increment $(<0.2 \mathrm{~s})$ in an intermediate storage reservoir (ISR) and then quantitatively transfer a portion of this sample to either a slow-response sensor or a specific long-term reservoir. Figure 3 shows the schematic of the DES used in this study. The ISR consisted either of a Teflon chamber (Fig. 3a, $\mathrm{V}=300 \mathrm{~cm}^{3}$, i.d. $=3.6 \mathrm{~cm}$ ) or a $4 \mathrm{~m}$ long, $1.27 \mathrm{~cm} \mathrm{o.d.} \mathrm{Teflon}$ tube $\left(\mathrm{V}=314 \mathrm{~cm}^{3}\right.$, Fig. $\left.3 \mathrm{~b}\right)$ which served as both an inlet and an ISR. Note that in Fig. 3a, the same 4-m tube was also used as an inlet to bring air near the sonic anemometer path to the sampler. Flow through the ISR/inlet was $>80 \mathrm{sLpm}$, resulting in a residence time of $\sim 0.2 \mathrm{~s}$. This lag was used to synchronize the DES with the correct $w(\mathrm{t})$. Fast shutoff solenoid valve(s) (V0, V1) were used to either isolate (Fig. 3a) or stop the flow (Fig. 3b) in the ISR. The hypothesis underlying our use of tubing as both an inlet and an ISR in Fig. $3 \mathrm{~b}$ is that, once the flow is stopped, axial mixing within the ISR is negligible and therefore the sample in the ISR retains its temporal signature along the length of the tube. This is not exactly true as the quick stoppage of flow results in some axial mixing and contamination with external air at the open end of the inlet. Tests in the lab under field conditions 


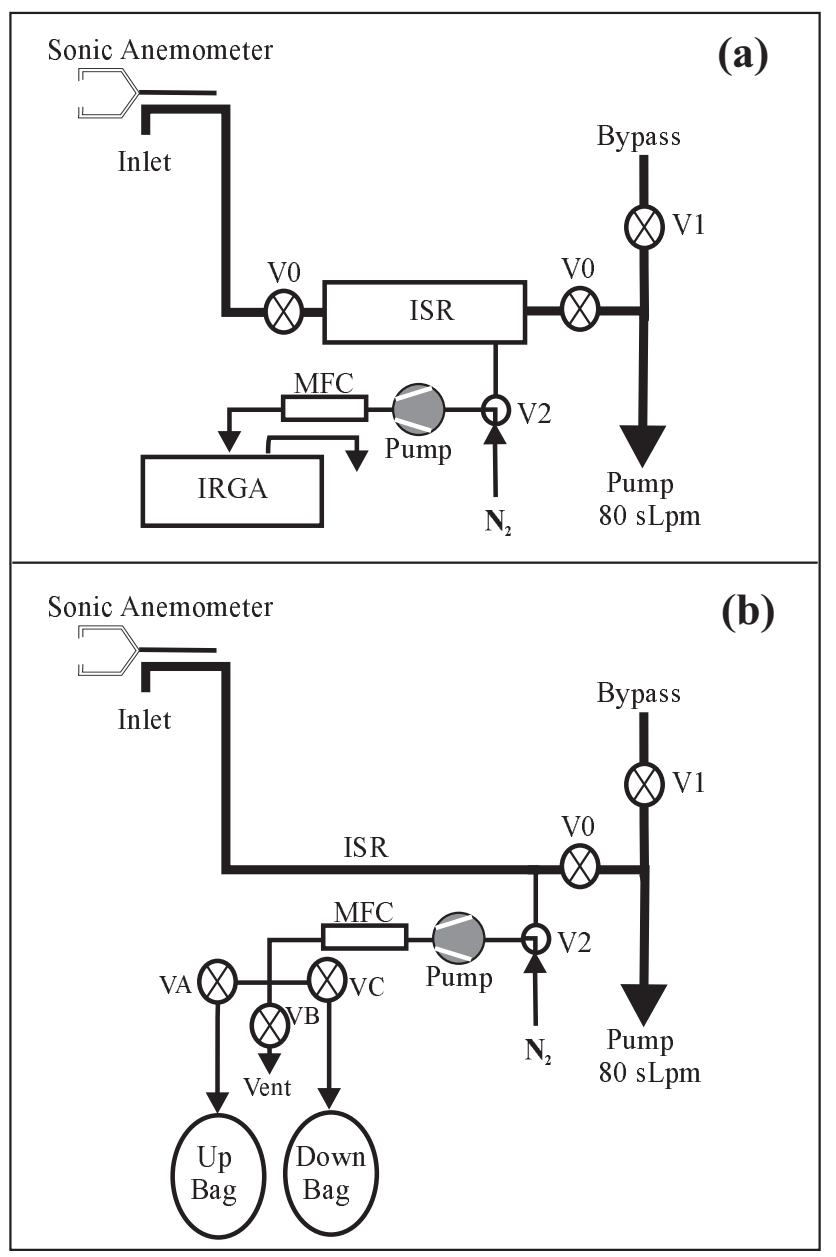

Fig. 3. (a) Schematic of the DES (in DEC mode) used for measuring $\mathrm{CO}_{2}$ fluxes at the Niwot Ridge site. (b) Schematic of the DES (in DEA mode) used for isoprene fluxes measured at the UMBS/PROPHET site.

using $\mathrm{CO}_{2}$ and $\mathrm{CO}_{2}$-free air (and detection with an IRGA) indicated that $<16 \%$ of the total ISR sample air was contaminated with external air $\left(\sim 50 \mathrm{~cm}^{3}\right.$ near the inlet). The maximum sample volume taken out of the ISR during a $25 \mathrm{~s}$ period was only $2 / 3$ of the total ISR volume; thus, the contaminated air was avoided. This also corresponds to a shorter sampling time resolution of $0.14 \mathrm{~s}$; however, due to some axial mixing during the flow stoppage, a more conservative estimate of our time resolution is $\sim 0.18 \mathrm{~s}$. Our actual sampling time resolution is dependent on $w-\left(\right.$ smaller $w_{i}^{\prime}$ leads to smaller volume taken from the ISR); however since the flux contribution of eddies at this short time resolution is small, this variable time resolution does not bias the final flux measurements. An advantage of this configuration over the closed chamber in Fig. 3a is that the system remains near ambient pressure through-out. This minimized problems with leaks and water condensation.
A sampling valve (V2) located just upstream of the shutoff valve was used to select between a "zero" gas or extracting a sample from the ISR via a small diaphragm pump (KNF Neuberger, UNMP30). Downstream of the sampling valve, the configuration could be changed depending on the mode of operation (DEC or DEA). For DEC, the sample air was transferred to an Infrared Gas Analyzer (IRGA, Licor, LI6251, Fig. 3a) run in absolute mode and periodically calibrated using the same $\mathrm{CO}_{2}$ standard as the EC measurements (which calibrate automatically). Analog signals from the IRGA were measured at $10 \mathrm{~Hz}$ by the DES system and averaged over a $10 \mathrm{~s}$ dispense time. For DEA (Fig. 3b), the sample air was pulled through a pump, a mass flow controller (for volume measurement) and then a manifold of solenoid valves (VA, VB and VC) to select either an up/down reservoir or a vent exiting the sampler. The dead volume between the cross and valves VA-VC was kept as small as possible $(<1 \%$ of a typical dispense volume) as well as the volume in the connecting tubing from VA-VC to the bags $\left(<2 \mathrm{~cm}^{3}\right)$ to minimize carry over effects. Laboratory tests showed no losses of our target species (isoprene or $\mathrm{CO}_{2}$ ) upon passage through the sampling pump.

The typical DES operating sequence consisted of three steps. (1) Flushing of the ISR ( $\mathrm{t}_{f l} \sim 4$ to $5 \mathrm{~s}$ ) while sampling a "zero" gas (via V2, Fig. 3). (2) The ISR flow was stopped rapidly ( $<1 \mathrm{~ms}$ ) by V0 (along with opening of V1) and the sampling valve (V2) switches, extracting a sample from the ISR (Flow=200 to $400 \mathrm{sccm}$ ). (3) After allowing time to flush the connecting lines and the sensor ( 2 to $10 \mathrm{~s}$ ), the sample gas concentration was either measured by the analyzer (DEC), or dispensed to the proper reservoir (DEA). The dispense time $\left(\tau_{d}\right)$ in DEA mode was determined by the vertical velocity, $w_{i}$, at the time the ISR flow was stopped.

$\tau_{d}(i)=k_{f}\left|w_{i}^{\prime}\right|$, such that $V_{i}^{ \pm}=(F l) k_{f}\left|w_{i}^{\prime}\right| \delta^{ \pm}$

where $F l$ is the flow rate $\left(\mathrm{m}^{3} \mathrm{~s}^{-1}\right)$ and $k_{f}$ is a scaling factor $\left(\mathrm{s}^{2} \mathrm{~m}^{-1}\right)$ relating the total allowable dispense time $\left(\tau_{\text {tot }}\right)$ to an estimated maximum vertical velocity $\left(w_{\max }\right), k_{f}=\tau_{\text {tot }} / w_{\max }$. Note that $(F l) k_{f}$ is the proportionality constant, $k$, defined in Eq. (5) with units of $\mathrm{m}^{2} \mathrm{~s}$. The selection of $w_{\max }$ at the beginning of a flux averaging period has a direct influence on the rate at which the reservoirs are filled. Underestimation of $w_{\max }$ can lead to samples with $w_{i}^{\prime}>w_{\max }$. Under these conditions, the dispense cycle is terminated at $\tau_{\text {tot }}$, thereby causing some volume to be "missed". However, a conservative (i.e., large) $w_{\max }$ leads to small total sample volumes which may be detrimental to the concentration determination. Currently, $w_{\max }$ is estimated by $0.7\left|w_{\max }\right|$ from the previous flux period using the raw $10 \mathrm{~Hz} w$-data. We have empirically found that a multiplicative factor between $0.6-0.7$ can be used to reduce $w_{\max }$ without causing a significant loss of sample volume $(<5 \%)$. 
Once the correct volume of sample is dispensed, the DES reverts to a "Standby" mode which is identical to the ISR flush mode until $\tau_{\text {tot }}$ is reached and the cycle begins again. The total cycle time (time between samples, $\Delta \mathrm{t}$ ) was between 15 to $30 \mathrm{~s}$. In the Niwot Ridge experiment, fluxes were averaged over $30 \mathrm{~min}$, whereas during the UMBS study, we used a $T_{\text {avg }}$ of $60 \mathrm{~min}$ to increase the number of disjunctly measured samples/flux period (120 or 180) which allowed us to collect enough volume in our reservoirs to do replicate concentration measurements.

The reservoirs for the isoprene measurements were Tedlar bags (4L) similar to those successfully used previously for isoprene with the REA technique (Bowling et al., 1998; Westberg et al., 2001). Concentrations of isoprene in the bags were measured by two gas chromatography systems both equipped with a photoionization detector (denoted as "WSU" and "NCAR" systems). The WSU GC/PID (Hewlett-Packard, model 5890) was used between days 195 to 202 and the NCAR GC/PID (FM-2000, CMS Research) used on days 202,213 to 214 . A sample ( 300 to $500 \mathrm{~cm}^{3}$ ) of gas from each bag was pre-concentrated either cryogenically (WSU) or on an adsorbent cartridge (NCAR) before injection into the GC. Two to three replicate samples from each bag were measured and averaged. Replicate concentration measurements were typically within $8 \%$ on both chromatographic systems. However, the contribution to the error in the flux is due to the difference between the up and down concentrations $\left(c^{+}-c^{-}\right)$. Propagating the errors in $c^{+}$and $c^{-}$showed that the error contribution to the flux was $\sim 36 \%$ on average.

The GCs were calibrated by sampling from bags filled with a standard containing $12 \mathrm{ppb}$ isoprene in nitrogen. Calibration standards used by the various measures (FIS, PTRMS and GC methods) were all intercalibrated using the PTRMS and found to agree within 15\%. Intercomparison of calibration standards using the two GC systems were also in very good agreement $( \pm 10 \%)$. Three of the DEA sampling bags (one complete flux sample - up and down reservoirs - plus a third sample) were sampled on both chromatographic systems for intercomparison. On average, the concentrations agreed to within $20 \%$; however, the concentration differences $\left(c^{+}-c^{-}\right)$on the single flux run showed a difference of $48 \%$, showing the effect of the error propagation on the final flux measurement. This illustrates one of the important concerns when employing the DEA technique as discussed in Sect. 2.4.

Data acquisition and valve control was accomplished using a National Instruments DAQ card (DAQ1200) in a laptop computer. Wind velocity data from the sonic anemometer was also read into the same laptop via an RS-232 connection. The DES was run by an in-house Labview program (National Instruments) which also incorporated the sonic anemometer data stream and synchronized all of the data streams and valve control. At Niwot Ridge a second anemometer was used (Applied Technologies, SATI-K) for the DEC measure-
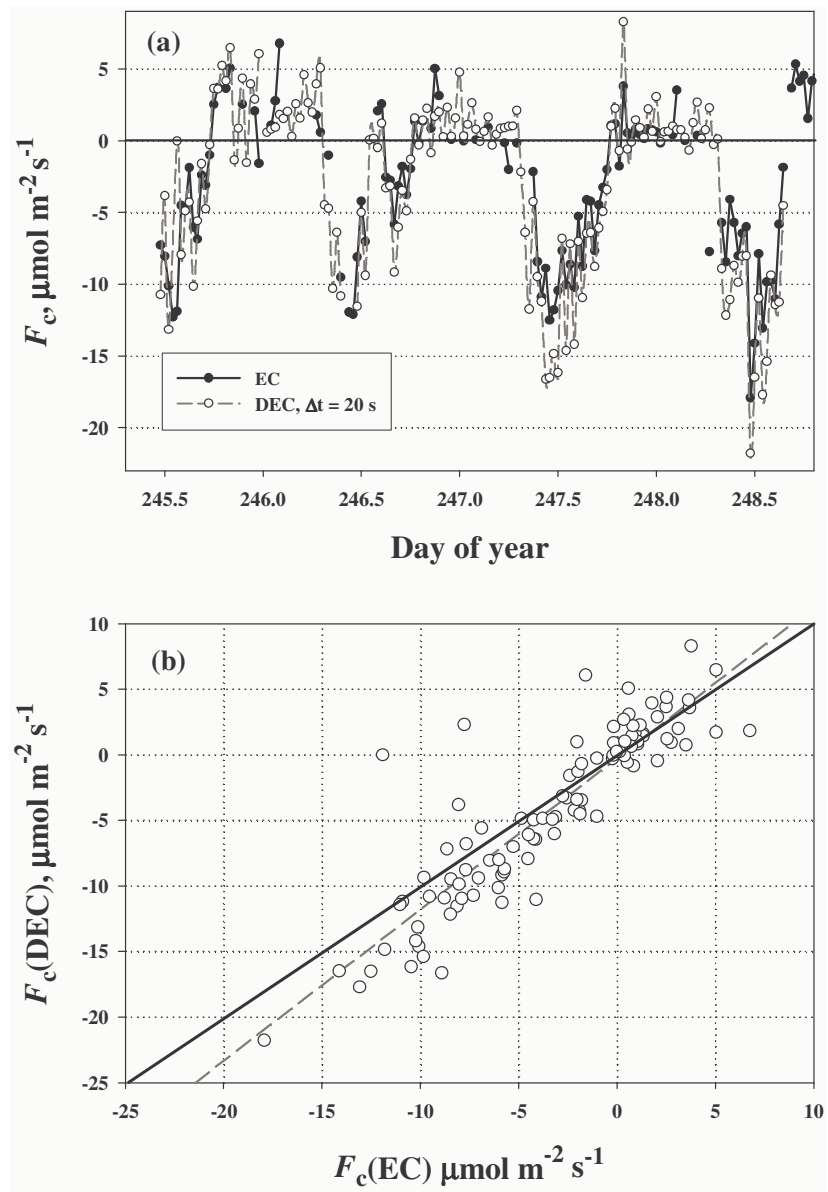

Fig. 4. (a) $\mathrm{CO}_{2}$ fluxes measured over 3 consecutive days at the Niwot Ridge AmeriFlux site by EC (•) and DEC (o). (b) Plot of the DEC-measured $\mathrm{CO}_{2}$ fluxes vs. EC fluxes. Solid line is the 1:1 line, Dashed line is the linear least squares fit $\left(\mathrm{y}=-0.3+1.15 \mathrm{x}, R^{2}=0.80\right)$.

ments; whereas at UMBS, the same anemometer was used for the $\mathrm{EC}, v \mathrm{DEC}$ and DEA measurements.

\section{Results and discussion}

\subsection{DEC/EC intercomparisons}

We initially used our DES sampler in DEC mode as a way to verify that we were achieving the necessary temporal resolution and that we were aligning the concentration measurements properly with the fast vertical wind velocities. Figure 4 shows the comparison over three days of $\mathrm{CO}_{2}$ fluxes measured by our DES sampler (with $\Delta \mathrm{t}=20 \mathrm{~s}$ ) and the eddy covariance fluxes measured at the Niwot Ridge AmeriFlux site. Concentrations measured by both IRGAs were within $\pm 5 \mathrm{ppm}$ ( $<2 \%$ difference). The coordinate systems for both EC and DEC were rotated such that $\bar{v}=\bar{w}=0$ (using the $10 \mathrm{~Hz}$ data for DEC) for each flux averaging period as described by Kaimal and Finnigan (1994). Rotating the DEC 
measurements to $\bar{w}_{\text {disj }}=0$ made no measurable difference in the intercomparison. Flow calculations suggested using a $0.2 \mathrm{~s}$ delay due to transport through the inlet. Cross correlation (using the maximum covariance) between our disjunctly sampled $c_{i}$ and $w_{i}$ resulted in a $0.3 \mathrm{~s} \mathrm{lag}$, in good agreement with flow calculations. The $0.1 \mathrm{~s} \mathrm{lag}$ difference did not significantly affect the computed fluxes.

The closed-path EC system contains a heat exchanger so that density corrections (WPL corrections, Webb et al., 1980) due to sensible heat were not necessary. As the sampling flow for the DEC passed through a diaphragm pump and a flow controller, we assume that the gas sample equilibrated to a constant temperature before measurement. We did not apply WPL corrections for water vapor to either the DEC or EC. Although this needs to be done to measure the true $\mathrm{CO}_{2}$ flux, it does not affect the intercomparison of the two techniques. Overall there is good agreement between the two techniques; however the DEC fluxes were typically $\sim 15 \%$ larger (Fig. 4b) over 104 flux averaging periods. We do not have a conclusive reason for this small discrepancy; however, this is well within the increased statistical uncertainty of $\pm 30 \%$ (Fig. 2b) for the DEC measurements. It is possible that temperature fluctuations in the DEC sampling flow were not completely eliminated before entering the IRGA which would result in an overestimation of the flux. However, the overall agreement suggests that our DES was successfully capturing air samples at the necessary time resolution and synchronizing these with the proper vertical wind velocity.

\subsection{Effects of nonzero $\bar{w}$ for Accumulation techniques}

All accumulation methods (EA, DEA and REA) are sensitive to offsets in $\bar{w}$ (Hicks and McMillan, 1984; Businger and Oncley, 1990; Bowling et al., 1998). These accumulation methods all need an estimate of $\bar{w}$ to determine what is an updraft or downdraft. Furthermore, these sampling decisions (updraft vs. downdraft) must be made in real time without prior knowledge of the wind statistics. This is in contrast to the eddy covariance measurements in which the coordinate reference frame can be rotated during post processing to remove or minimize nonzero mean vertical wind velocity before calculation of the flux. Attempts have been made to use real-time low pass filters to remove offsets in $\bar{w}$ for the REA technique (Pattey et al., 1993; Baker et al., 1992; Guenther et al., 1996); however, these can impart phase shifts in the filtered signal (Bowling et al., 1998) and is tantamount to using a variable coordinate frame. In the current study, we have employed using a constant $w$-offset measured from the prior flux averaging period. This serves to reduce the "mean" term in Eq. (16), but it is not a true rotation of the coordinate reference frame, which involves interactions between the three wind axes.

To test the effects of nonzero $\bar{w}$ (or $\bar{w}_{\text {disj }}$ for DEA), we used fast temperature and isoprene data from the UMBS/PROPHET experiment to simulate the eddy accumu-

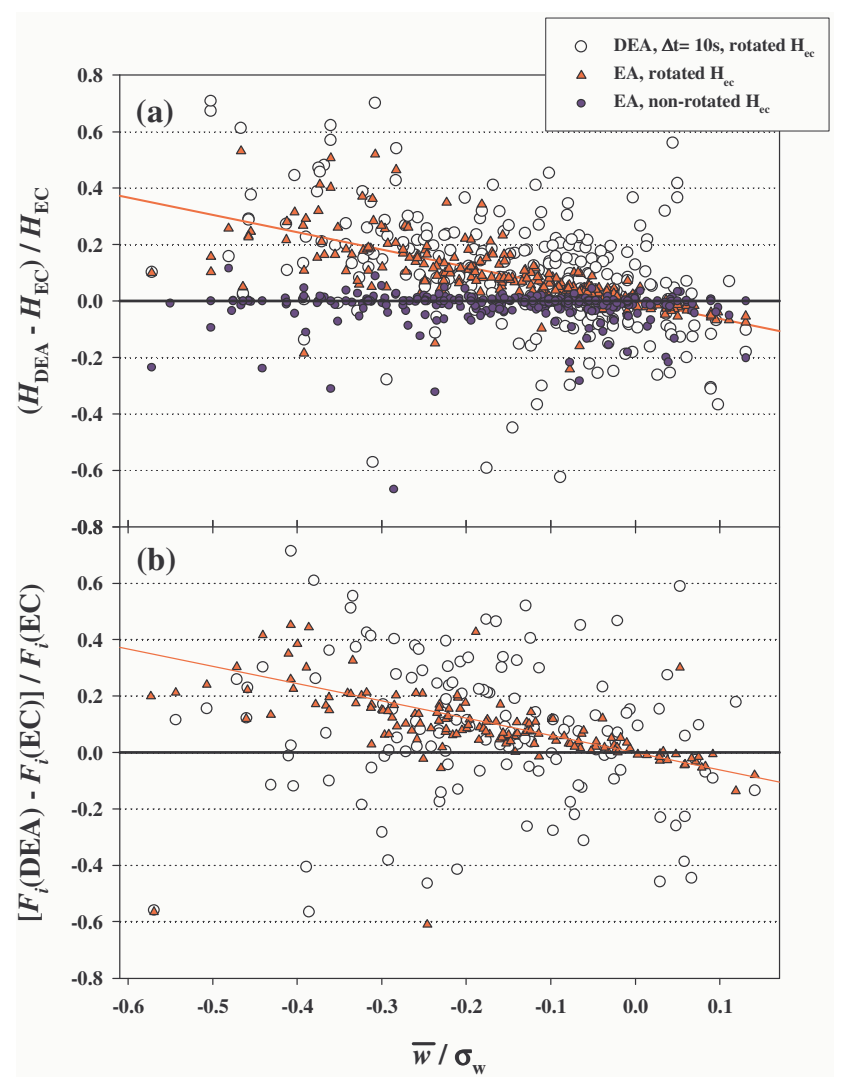

Fig. 5. (a) Plots of the heat flux difference between simulated DEA and EA fluxes and the flux derived via EC (and normalized by the EC flux) vs. $\bar{w} / \sigma_{w}$. Data simulated were from Days 195 to 216 at the UMBS/PROPHET site. (b) Similar plot for simulated isoprene fluxes using the $10 \mathrm{~Hz}$ FIS data (using only Days 195 to 203). Only data with $H_{e c}>25 \mathrm{~W} \mathrm{~m}^{-2}$ were used in both panels. For DEA, the time series were disjunctly sampled at $\Delta \mathrm{t}=10 \mathrm{~s}(\mathrm{o})$. Red line in both plots is the linear regression of the EA simulation compared to the rotated EC fluxes.

lation process - both with continuous and disjunct sampling. Sonic anemometer temperatures or isoprene concentrations were partitioned and "accumulated" into up and down bins proportional to $w_{i}^{\prime}$. EA/DEA fluxes were derived via the simplified Eq. (10) and their differences from the EC flux (and normalized by the EC flux) are shown in Fig. 5 as a function of $\bar{w}$ normalized by $\sigma_{w}$. In Fig. 5a, it can be seen that EA fluxes show a trend with a negative slope when compared to EC fluxes where the coordinate system has been rotated to remove any $w$-bias ( $\bar{w}=0$, Kaimal and Finnigan, 1994). This is similar to that noted previously for the REA technique (Businger and Oncley, 1990; Pattey et al., 1993; Bowling et al., 1998). However, when EC fluxes were not rotated, excellent agreement was obtained between the two techniques. We also obtained excellent agreement between EA and EC when the coordinate system was rotated such that $\bar{w}=0$ prior to either the "accumulation" process or calculation of the EC flux (data not shown). It appears the negative trend in EA 
(and likely REA) with $\bar{w}$ when compared to $\mathrm{EC}$ is indicative of the amount of contamination in the $w$-measurement by the horizontal wind components ( $u$ and $v$ ) and illustrates the need for the use of consistent coordinate reference frames. The slope of this trend is likely related to the sonic orientation with respect to the main wind streamlines and, thus, varies with experimental setup. As can be seen in Fig. 5, normalized vertical wind biases of \pm 0.25 can lead to $\pm 15 \%$ errors in the flux in this experiment.

For the disjunct sampling simulation followed by accumulation, the negative trend with $\bar{w}$ is somewhat obscured by the overlying statistical error for both sensible heat and isoprene fluxes (Fig. 5a and b). However, it does not appear that the reduced statistical sampling exacerbates the observed EA bias in any way. In these simulations, we used the $\bar{w}$ from the previous flux period as our estimate for $\bar{w}_{\text {disj }}$ from which to make sampling decisions to accurately simulate our observational method. This selection of $\bar{w}_{\text {disj }}$ tended to give better simulated results when using the simplified Eq. (10) (i.e., a smaller mean term in Eq. 16) to compute the DEA fluxes, but did not remove the bias shown in the EA simulations. Finally, the propensity of negative values for $\bar{w}$ during this study led to an overall overestimation of both the simulated DEA sensible heat (7\%) and isoprene (10\%) fluxes on average relative to eddy covariance.

\subsection{DEA/DEC/EC intercomparisons}

As part of a continuing long-term study of isoprene emission (Pressley et al., 2005), EC fluxes using the FIS were measured continuously throughout the entire experiment. DEA fluxes were measured over 10 days for a total of 62 1-h flux periods. During two of those days, fluxes were also measured using the PTRMS system, such that three different methods were directly compared (EC-FIS, $v$ DEC-PTRMS, DEA-GC). The $1 \mathrm{~h}$ averaging period of the DEA resulted in 120 or 180 disjunct samples/flux period (i.e., $\Delta \mathrm{t}=20$ or $30 \mathrm{~s}$ ). The EC-FIS and $v$ DEC-PTRMS fluxes were computed for shorter flux periods (30 min.) and averaged up to one hour for direct comparison with the DEA. No density-based corrections (Webb et al., 1980) were applied to any of the measured fluxes as they have been shown to be insignificant for species such as isoprene where the flux/concentration ratio is large (Pattey et al., 1992). The coordinate systems for both EC and $v$ DEC measurements were rotated such that $\bar{v}=\bar{w}=0$ for each individual flux period (Kaimal and Finnigan, 1994); the DEA system coordinate system was based on the $\bar{w}$-value from the previous sampling period. We used a $0.2 \mathrm{~s}$ delay time to account for transit time in the ISR/inlet of the DEA as suggested by flow rate measurements and our previous DEC cross correlation measurements. DEA simulations using sensible heat flux data and varying the lag between the $w$ and $T_{v}$ time series indicated only small losses in flux $(\sim 6 \%)$ for errors in lag time of up to 3 samples $(0.3 \mathrm{~s})$. Any small error caused by improper lag selection is likely

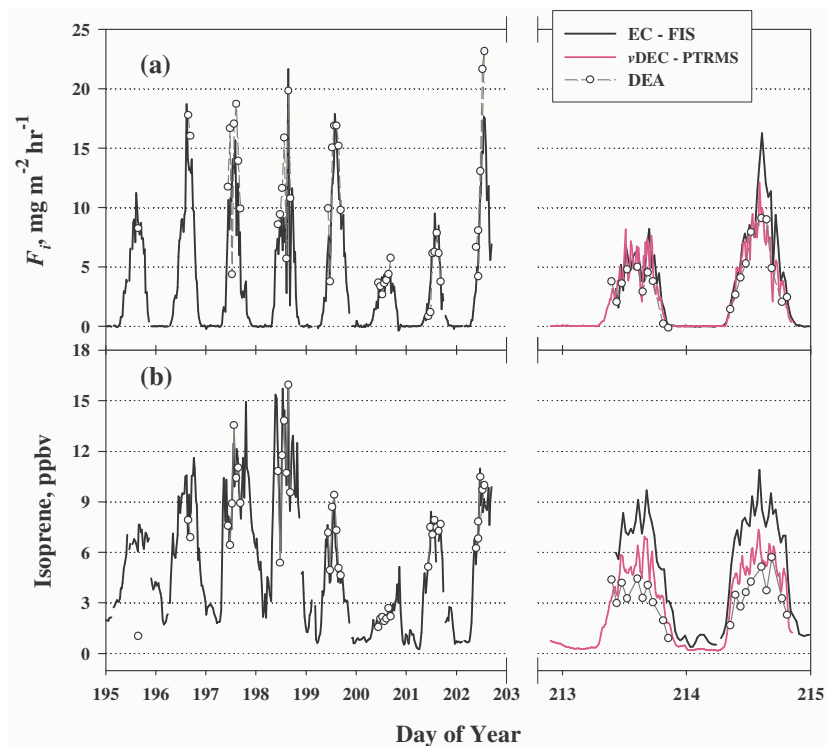

Fig. 6. Time series of (a) isoprene fluxes, $F_{i}$, and (b) isoprene mixing ratios, measured by EC-FIS (black solid line), $v$ DEC-PTRMS (magenta), and DEA-GC (open circles). Concentrations measured by the DEA-GC are the average of the up and down reservoirs.

overwhelmed by the overall uncertainty in the flux measurement (discussed below). Figure 6 shows a time series of the measured fluxes (at the different time resolutions) and concentrations from all three systems. As seen in the figure, both concentrations and fluxes were in very good agreement during most periods, noting that the diurnal trends and midday variability were reproduced by all three systems.

Concentration measurements between the DEA and the FIS were in very good agreement $( \pm 15 \%)$ except on the last two days when the EC-FIS tended to give significantly higher concentrations relative to both the DEA and the PTRMS. The FIS can respond to other reactive olefinic compounds in the atmosphere (Guenther and Hills, 1998). Measurements by the PTRMS indicated that the two primary interferences were methyl vinyl ketone (MVK) and methacrolein (MACR), both oxidation products of isoprene. However, using relative response factors derived by Guenther and Hills (1998), these compounds could only explain between 5 and $15 \%$ of the disagreement. It should also be noted that the FIS instrument had suffered an instrumental shutdown due to a power outage the previous night (note there are no measurements on the night between days 212-213), which may have resulted in an undetected signal offset. In any case, it is highly unlikely that any of these interfering compounds were emitted or deposited at a rate which could affect the isoprene flux measurement of the FIS. This is borne out in the good agreement of EC-FIS flux measurements with the other two techniques. 


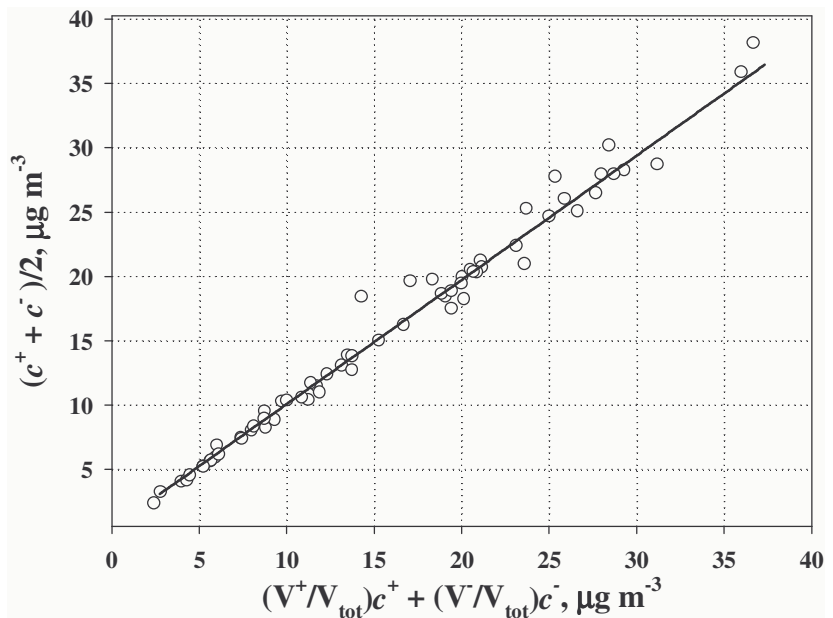

Fig. 7. Comparison of isoprene densities computed assuming equal volumes in the up and down reservoirs and that computed from a volume-weighted average.

Validation and testing of the EC-FIS and the $v$ DECPTRMS techniques have been discussed at length in other publications (Pressley et al., 2005; Karl et al., 2002) and will not be repeated here. Several checks were made to insure that the DEA was sampling correctly. Within a given flux period, volume in both reservoirs was observed to be accumulated linearly with increasing $\sum\left|w_{i}^{ \pm}\right|$. Furthermore, plots of $V^{ \pm}$vs. $\sum\left|w_{i}^{ \pm}\right| / w_{\max }$ for a given sampling flow rate (varied between 250 to $450 \mathrm{sccm}$ ) and total dispense time setting (20 or 30 s) were extremely linear (with identical slopes for $V^{+}$and $V^{-}$) indicating that our sampling system was indeed delivering volume properly (see Eq. 21). Also, the volume difference $\left(V^{+}-V^{-}\right)$was observed to vary linearly with $\bar{w}_{\text {disj }} / w_{\max }$ as expected. Flow rate tests in the field without the bags in place verified that the proper reservoirs (up/down) were selected and that the correct volume was quantitatively transferred. Using a $w_{\max }$ multiplier of 0.7 (see Sect. 3.3), the average amount of volume missed was $0.3 \%$ (with a maximum value of $6 \%$ ) which had no impact on the concentrations, or more importantly, the concentration differences used in the flux calculations.

Inclusion of the mean term (Eq. 16) in the flux calculations led to only a $4 \%$ lower flux (on average) relative to using the simplified Eq. (10). This was confirmed by computing the isoprene concentration from the accumulated up/down samples as both an unweighted and a volume-weighted average density (see Eq. 16). Figure 7 shows that there is little difference between these two determinations of the mean density, suggesting that the "mean" term in Eq. (16) was small. Finally, a direct comparison of the flux ratio of DEA to EC (or $v \mathrm{DEC})$ revealed an average near unity $(1.06 \pm 0.39,1 \sigma, \mathrm{N}=62$ relative to the FIS and $0.94 \pm 0.39,1 \sigma, \mathrm{N}=19$ compared to the PTRMS).
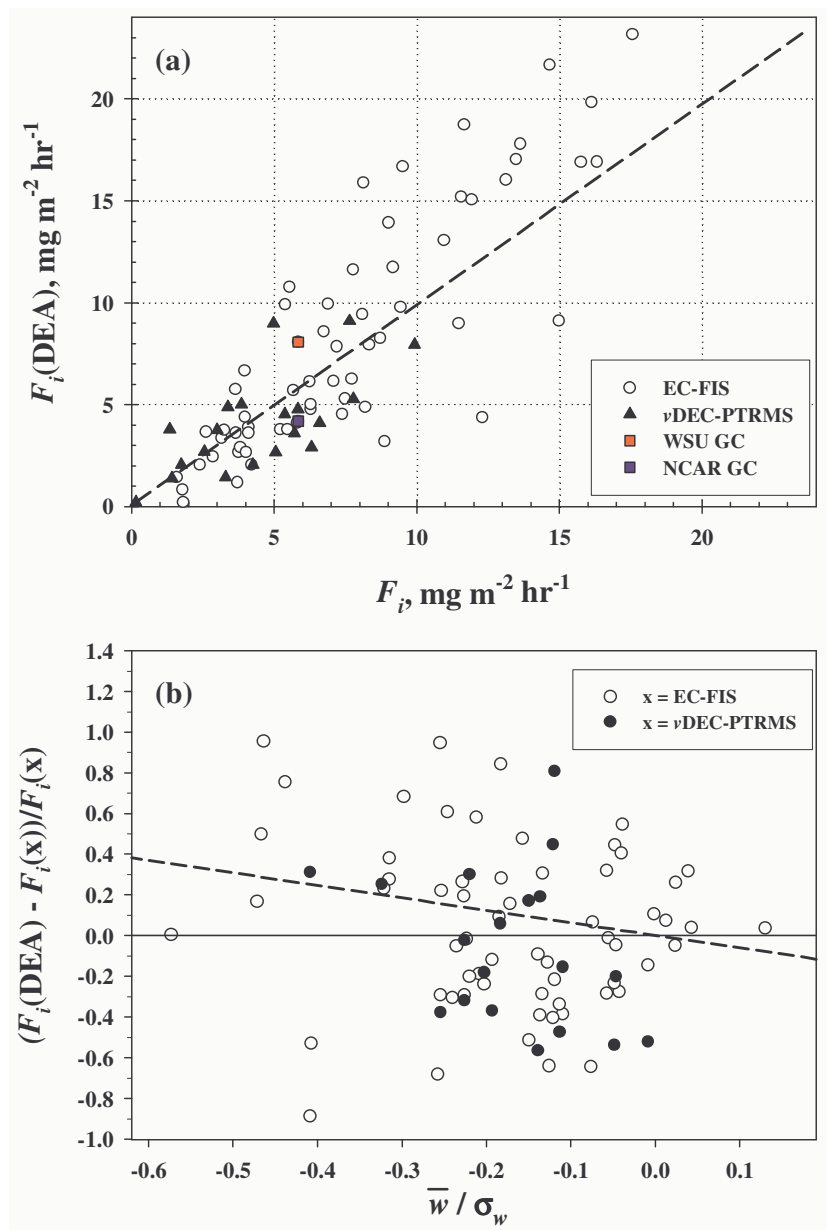

Fig. 8. (a) Plot of the DEA-GC fluxes vs. the EC-FIS and $v$ DECPTRMS fluxes. The dashed line drawn is the $1: 1$ line. The two solid squares denote the one flux sample where the reservoirs were analyzed by both GC systems (red = WSU, blue $=$ NCAR) and compared to the EC-FIS system. (b) Plot of $F_{i}(\mathrm{DEA})-F_{i}(\mathrm{x}) / F_{i}(\mathrm{x})$ where $\mathrm{x}=\mathrm{EC}$-FIS $(\circ)$ or $v$ DEC-PTRMS $(\bullet)$ vs. $\bar{w} / \sigma_{w}$. The dashed line represents the expected bias from EA simulations shown in Fig. 5.

Figure 8a shows a comparison of the DEA-GC relative to both the EC-FIS and DEC- $v$ PTRMS measurements. There is a substantial amount of scatter in the comparison between the DEA and either the FIS or $v$ DEC measurements. This is due to the cumulative effects of uncertainty from both (1) the reduced statistical sampling ( $\pm 20-25 \%$, see Fig. $2 b)$ and (2) the measurement of $\Delta C( \pm 36 \%$ on average, Sect. 3.3), leading to a total uncertainty of 40 to $44 \%$ for a given DEA flux measurement. Furthermore, as noted from our simulations in Sect. 4.2, the UMBS/PROPHET sonic orientation tended to give negative $\bar{w}$ values, thereby leading to an overestimate in the DEA flux relative to eddy covariance. The average value of $\bar{w} / \sigma_{w}=-0.18$; therefore, based on our earlier simulations, we would expect $\sim 11 \%$ overestimate of the flux, in good agreement with the average value obtained in 


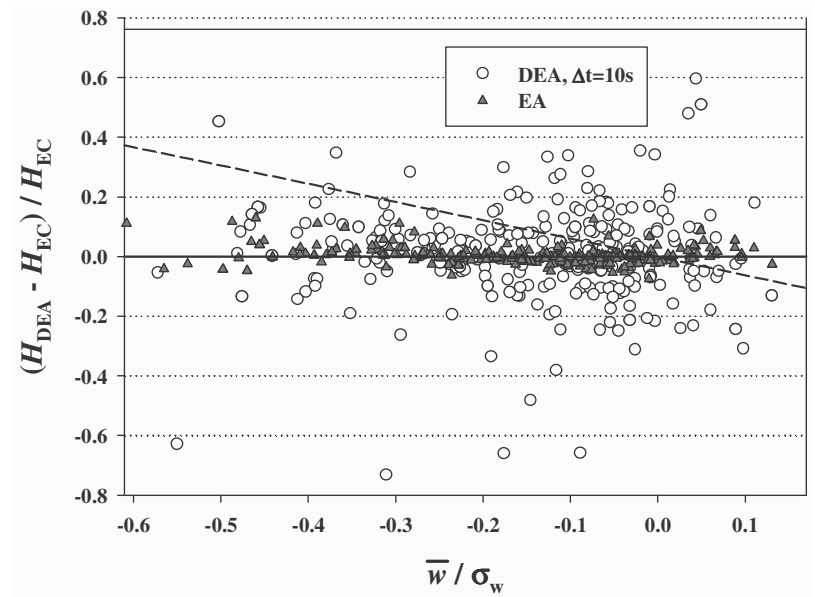

Fig. 9. Comparison between simulated DEA or EA sensible heat fluxes and those derived via EC (and normalized by the EC flux) as a function of $\bar{w} / \sigma_{w}$. Both the EC and DEA coordinate frames have been rotated using the planar fit method (see text). Data is from the UMBS/PROPHET experiment as in Fig. 5 and the dashed line represents the bias observed in Fig. 5.

comparison with EC-FIS. Although the large uncertainty in the individual DEA fluxes make it difficult to observe a clear trend with $\bar{w}$ (Fig. 8b), periods where the DEA appears to measure significantly larger fluxes than the EC-FIS system often coincided with large negative $\bar{w}$ values.

A can be seen in Fig. 8a, the DEA tends to consistently overestimate the isoprene flux at high flux values relative to the EC-FIS. The exact nature of this is unclear as only some of these flux periods exhibited large negative $\bar{w}$ which could result in a significant overestimation. Average concentration measurements between the DEA and FIS systems during these periods were typically within $10 \%$ and wind velocities in both systems originated from the same sonic anemometer. However, the high degree of uncertainty in the DEA measurements (and, to a lesser degree, the EC measurements) along with the expected error due to nonzero $\bar{w}$ make it difficult to conclusively ascribe this to an overall bias in the DEA flux. Overall the measurements show good agreement between the techniques within the estimated errors $( \pm 40 \%$ for the DEA).

The fairly large uncertainties and biases associated with the DEA technique are an area of concern and minimization of these would be desirable. As described in Sect. 2.2 and 2.3, to maintain a large enough dynamic sampling range, it was necessary to have a $\Delta \mathrm{t} \geq 10 \mathrm{~s}$ in the system described here. Therefore, it is difficult to reduce the sampling error in the DEA experiment without resorting to excessively long flux averaging periods. It is likely that the concentration measurement precision can be reduced, but this will be dependent on the target species and the analytical method used. However, it is possible to reduce the bias caused be improper coordinate frame, at least for fixed, tower-based flux measurements.
Although typical run-to-run coordinate rotation is not applicable to accumulation techniques, the possibility of rotating to long-term mean wind streamlines can be integrated into the on-line decision making required of accumulation methods. Several of these rotation methods have been described in previous studies (Wilczak et al., 2001; Lee, 1998; Baldocchi et al., 2000). The planar fit method described by Wilczak et al. (2001) uses fixed angles derived from wind velocity data to rotate the coordinate frame into a plane parallel to the underlying surface. These angles can be used in an on-line fashion to minimize $\bar{w}$. Figure 9 shows a simulation of heat fluxes from the UMBS/PROPET data showing the effect of using the planar fit method of rotation. Rotation angles were computed following Wilczak et al. (2001) and applied to both the EC and DEA/EA (applied on-line) sensible heat fluxes. As seen in the figure, no systematic bias with $\bar{w}$ was observed. Furthermore, it has been shown that the run-to-run coordinate rotation methods act to adversely filter the calculated EC flux (Wilczak et al., 2001; Finnigan et al., 2003) and that using long-term mean streamline coordinate systems is advisable for EC measurements as well. Concerning accumulation techniques, the major drawback of using long-term coordinate systems such as the planar fit is that it requires sufficient wind velocity data (often several days to a few weeks) to determine the rotation angles prior to sampling. However, with the expanding number of flux tower sites designed for long term flux measurements; this would not appear to be a significant problem.

\section{Conclusions}

In this paper we have re-examined the method of disjunct eddy sampling (DES) and its application towards measuring ecosystem-level fluxes. Since the use of DEC is increasing (Karl et al., 2002; Grabmer et al., 2004; Held et al., 2007; Langford et al., 2008), we have presented simulations which further substantiate the statistical limitations first pointed out by Lenschow et al. (1994). We have also developed a sampler that can be used for disjunct eddy sampling in either a covariance (DEC) or accumulation (DEA) mode. A detailed description of this system was presented along with additional operational considerations to serve as guides for other investigators interested in this technique. Flux measurements using both modes of this sampler were compared to the more established method of eddy covariance and exhibited good agreement; however, there was a fairly large uncertainty $(\sim \pm 40 \%)$ due both the reduction in statistical sampling and the analytical measurement precision. Furthermore, the underlying bias with mean vertical wind velocity was shown to result in an overall overestimate of the DEA fluxes $(\sim 11 \%)$. It is likely in the future that biases due to nonzero mean wind velocity can be significantly reduced by using on-line rotation to long-term mean streamline 
coordinates (such as the planar fit method). This should not only be true for DEA, but for the more commonly used REA technique.

Even though the overall uncertainty can be significant, DEA provides a possible flux measurement technique that does not rely on similarity scaling and is applicable over similar landscapes as eddy covariance. For a variety of trace atmospheric gases and aerosols that cannot be measured rapidly, the DEA technique provides another viable alternative to other relative techniques such as flux gradients and relaxed eddy accumulation. It also appears possible to extend this technique to aircraft platforms in order to provide estimates of regional surface fluxes.

Acknowledgements. The authors would like to thank Mary Anne Carroll and the staff at the University of Michigan Biological Station for their support of this work. We would also like to acknowledge the UMBS AmeriFlux site for use of their meteorological data. We would also like to thank Sean Burns and Russell Monson at the Niwot Ridge AmeriFlux site for their help. We would also like to thank Paul Shepson of Purdue University for helpful discussions, and Steven Oncley and James Greenberg (both from NCAR) for useful comments concerning this work. We would also like to thank Pierre Prevost for his programming contributions early in this project. This work was funded by a grant from the National Science Foundation's (NSF) Biocomplexity program (Grant \#0119995). The National Center for Atmospheric Research is operated by the University Corporation for Atmospheric Research under the sponsorship of the National Science Foundation.

Edited by: J. Rinne

\section{References}

Ammann, C., Brunner, A. Spirig, C., and Neftel, A.: Technical Note: Water vapour concentration and flux measurements with PTR-MS, Atmos. Chem. Phys., 6, 4643-4651, 2006, http://www.atmos-chem-phys.net/6/4643/2006/.

Baker, J. M. Norman, J. M., and Bland, W. L.: Field-scale application of flux measurement by conditional sampling, Agr. Forest Meteorol., 62, 31-52, 1992.

Baldocchi, D., Finnigan, J., Wilson, K., and Paw U, K. T.: On measuring net ecosystem carbon exchange over tall vegetation in complex terrain, Bound-Lay. Meteorol., 96, 257-291, 2000.

Barket Jr., D. J., Hurst, J. M., Couch, T. L., Colorado, A., Shepson, P. B., Riemer, D. D., Hills, A. J., Apel, E. C., Hafer, R., Lamb, B. K., Westburg, H. H., Farmer, C. T., Stabenau, E. R., and Zika, R. G.: Intercomparison of automated methodologies for determination of ambient isoprene during the PROPHET 1998 summer campaign, J. Geophys. Res.-Atmos., 106(D20), 24301-24313, 2001.

Bowling, D. B., Turnipseed, A. A., Delany, A. C., Baldocchi, D. D., Greenberg, J. P., and Monson, R. K.: The use of Relaxed Eddy Accumulation to measure biosphere-atmosphere exchange of isoprene and other biological trace gases, Oecologia, 116, 306-315, 1998.

Businger, J. A. and Oncley, S. P.: Flux Measurement with Conditional Sampling, J. Ocean. Atmos. Tech., 7, 349-352, 1990.
Carroll, M. A., Bertman, S. B., and Shepson, P. B.: Overview of the Program for Research on Oxidants: Photochemistry, Emissions and Transport (PROPHET) summer 1998 measurements intensive, J. Geophys. Res.-Atmos., 106(D20), 24275-24288, 2001.

Cellier, P. and Brunet, Y.: Flux-gradient relationships above tall plant canopies, Agr. Forest Meteorol., 58, 93-117, 1992.

Denmead, O. T.: Micrometeorological methods for measuring gaseous losses of nitrogen in the field, in: Gaseous Loss of Nitrogen from Plant-Soil Systems, edited by: Freney, J. R. and Simpson, J. R., Martinus Nijhoff/W. Junk, The Hague, 133-157, 1983.

Desjardin, R. L.: Description and evaluation of a sensible heat flux detector, Bound-Lay. Meteorol., 11, 147-154, 1977.

Finkelstein, P. L., Ellestad, T. G., Clarke, J. F., Meyers, T. P., Schwede, D. B., Hebert, E.O., and Neal, J. A.: Ozone and sulfur dioxide dry deposition to forests: Observations and model evaluation. J. Geophys. Res.-Atmos., 105(D12), 15365-15377, 2000.

Finnigan, J. J., Clement, R., Malhi, Y., Leuning, R., and Cleugh, H. A.: A re-evaluation of long-term flux measurement techniques Part I: Averaging and coordinate rotation, Bound-Lay. Meteorol., 107, 1-48, 2003.

Foken, T. and Wichura, B.: Tools for quality assessment of surfacebased flux measurements, Agr. Forest Meteorol., 78, 83-105, 1996.

Fowler, D. and Duyzer, J. H.: Micrometeorological techniques for the measurement of trace gas exchange, in: Exchange of Trace Gases between Terrestrial Ecosystems and Atmosphere, edited by: Andreae, M. O. and Schimel, D. S., John Wiley \& Sons, New York, USA, 189-207, 1989.

Grabmer, W., Graus, M., Lindinger, C., Wisthaler, A., Rappengluck, B., Steinbrecher, R., and Hansel, A.: Disjunct eddy covariance measurements of monoterpene fluxes from a Norway spruce forest using PTR-MS, Int. J. Mass Spectrom., 239, 111115, 2004.

Guenther, A., Baugh, W., Davis, K., Hampton, G., Harley, P., Klinger, L., Vierling, L., Zimmerman, P., Allwine, E., Dilts, S., Lamb, B., Westberg, H., Baldocchi, D., Geron, C., and Pierce, T.: Isoprene fluxes measured by enclosure, relaxed eddy accumulation, surface layer gradient, mixed layer gradient and mixed layer mass balance techniques, J. Geophys. Res.-Atmos., 101, 18555-18567, 1996.

Guenther, A. and Hills, A.: Eddy covariance measurement of isoprene fluxes, J. Geophys. Res.-Atmos., 103(D11), 13145-13152, 1998.

Haugen, D. A.: Effects of sampling rates and averaging periods on meteorological measurements, Proc. Fourth Symp. On Meteorol. Observations and Instrumentation, Amer. Meteor. Soc., Denver, CO, USA, 15-18, 1978.

Held, A., Niessner, R., Bosveld, F., Wrzesinsky, T., and Klemm, O.: Evaluation and Application of an Electrical Low Pressure Impactor in Disjunct Eddy Covariance Aerosol Flux Measurements, Aerosol Sci. Tech., 41, 510-519, 2007.

Hicks, B. B. and McMillen, R. T.: A Simulation of eddy accumulation method for measuring pollutant fluxes, J. Clim. Appl. Meteorol., 23, 637-643, 1984.

Kaimal, J. C. and Finnigan, J. J.: Atmospheric Boundary Layer Flows: Their Structure and Measurement, Oxford Univ. Press, Oxford, 1994.

Karl, T., Guenther, A., Lindinger, C., Jordan, A., Fall, R., and Lindinger, W.: Eddy covariance measurements of oxygenated 
volatile organic compound fluxes from crop harvesting using a redesigned proton-transfer-reaction mass spectrometer, J. Geophys. Res.-Atmos., 106(D20), 24157-24167, 2001.

Karl, T. G., Spirig, C., Prevost, P., Stroud, C., Rinne, J., Greenberg, J., Fall, R., and Guenther, A.: Virtual disjunct eddy covariance measurements of organic compounds fluxes from a subalpine forest using proton transfer reaction mass spectrometry, Atmos. Chem. Phys., 2, 279-291, 2002, http://www.atmos-chem-phys.net/2/279/2002/.

Karl, T., Guenther, A., Spirig, C., Hansel, A., and Fall, R.: Seasonal variation of biogenic VOC emission above a mixed hardwood forest in northern Michigan, Geophys. Res. Lett., 30(23), 2186, doi:10.1029/2003GL018432, 2003.

Karl, T., Potosnak, M., Guenther, A. Clark, D., Walker, J., Herrick, J. D., and Geron, C.: Exchange processes of volatile organic compounds above a tropical rain forest: Implications for modeling tropospheric chemistry above a dense forest, J. Geophys. Res.-Atmos., 109, D18306, doi:10.1029/2004JD004738, 2004.

Katul, G., Hsieh, C., Bowling, D., Clark, K., Shurpali, N., Turnipseed, A., Albertson, J., Tu, K., Hollinger, D., Evans, B., Offerle, B., Anderson, D., Ellsworth, D., Vogel, C., and Oren, R.: Spatial variability of turbulent fluxes in the roughness sublayer of an even-aged pine forest, Bound-Lay. Meteorol., 93, 1-28, 1999.

Lamb, B., Westberg, H., and Allwine, G.: Biogenic Hydrocarbon Emissions from Deciduous and Coniferous Trees in the United States, J. Geophys. Res.-Atmos., 90, 2380-2390, 1985.

Langford, B., Davison, B., Nemitz, E., and Hewitt, C. N.: Mixing ratios and eddy covariance flux measurements of volatile organic compounds from an urban canopy (Manchester, UK), Atmos. Chem. Phys. Discuss., 8, 245-284, 2008,

http://www.atmos-chem-phys-discuss.net/8/245/2008/.

Lee, X.: On micrometeorological observations of surface-air exchange over tall vegetation, Agr. Forest Meteorol., 91, 39-49, 1998.

Lenschow, D. H., Mann, J., and Kristensen, L.: How long is long enough when measuring fluxes and other turbulence statistics? J. Ocean. Atmos. Tech., 11, 661-673, 1994.

Lenschow, D. H.: Micrometeorological techniques for measuring biosphere-atmosphere trace gas exchange, in: Biogenic Trace Gases: Measuring Emissions from Soil and Water, edited by: Matson, P. A. and Harris, R. C., Cambridge, Blackwell Science, 126-163, 1995.

Meyers, T. P., Huebert, B. J., and Hicks, B. B.: $\mathrm{HNO}_{3}$ Deposition to a Deciduous Forest, Bound-Lay. Meteorol., 49, 395-410, 1989.

Monson, R. K., Turnipseed, A. A., Sparks, J. P., Harley, P. C., ScottDenton, L. E., Sparks, K., and Huxman, T. E.: Carbon Sequestration in a high-elevation subalpine forest, Global Change Biol., 8, 1-20, 2002.

Pattey, E., Desjardins, R., Boudreau, F., and Rochette, P.: Impact of density fluctuations on flux measurements of trace gases: Implications for the relaxed eddy accumulation technique, Bound-Lay. Meteorol., 59, 195-203, 1992.

Pattey, E., Desjardins, R., and Rochette, P.: Accuracy of the relaxed eddy-accumulation technique, evaluated using $\mathrm{CO}_{2}$ flux measurements, Bound-Lay. Meteorol., 66, 341-355, 1993.
Pressley, S., Lamb, B., Westberg, H., Flaherty, J., Chen, J., and Vogel, C.: Long-term isoprene flux measurements above a northern hardwood forest, J. Geophys. Res.-Atmos., 110, D07301, doi:10.1029/2004JD005523, 2005.

Rinne, H. J. I., Delany, A. C., Greenberg, J. P., and Guenther, A. B.: A true eddy accumulation system for trace gas fluxes using disjunct eddy sampling method, J. Geophys. Res.-Atmos., 105, 24791-24798, 2000.

Rinne, H. J. I., Guenther, A. B., Warneke, C., DeGouw, J. A., and Luxembourg, S. L.: Disjunct eddy covariance technique for trace gas flux measurements, Geophys. Res. Lett., 28, 3139-3142, 2001.

Rinne, H. J. I., Guenther, A. B., Greenberg, J. P., and Harley, P. C.: Isoprene and monoterpene fluxes measured above Amazonian rainforest and their dependence on light and temperature, Atmos. Environ., 36, 2421-2426, 2002.

Rinne, H. J. I., Douffet, T., Prigent, Y., and Durand, P.: Field comparison of disjunct and conventional eddy covariance techniques for trace gas flux measurements, Environ. Pollution, 152, 630 635, 2008.

Ritter, J. A., Lenschow, D. H., Barrick, J. D. W., et al.: Airborne flux measurements and budget estimates of trace species over the Amazon Basin during the GTE/ABLE-2B Expedition, J. Geophys. Res.-Atmos., 95(D10), 16875-16886, 1990.

Schmid, H. P., Su, H.-B., Vogel, C. S., and Curtis, P. S.: Ecosystematmosphere exchange of carbon dioxide over a mixed hardwood forest in northern lower Michigan, J. Geophys. Res.-Atmos., 108(D14), 4417, doi:10.1029/2002JD003011, 2003.

Turnipseed, A. A., Blanken, P. D., Anderson, D. E., and Monson, R. K.: Energy budget above a high-elevation subalpine forest in complex topography, Agr. Forest Meteorol., 110, 177-201, 2002.

Turnipseed, A. A., Anderson, D. E., Blanken, P. D., Baugh, W. M., and Monson, R. K.: Airflows and turbulent flux measurements in mountainous terrain, Part 1. Canopy and local effects, Agr. Forest Meteorol., 119, 1-21, 2003.

Warneke, C., Luxembourg, S. L., DeGouw, J. A., Rinne, H. J. I., Guenther, A. B., and Fall, R.: Disjunct eddy covariance measurements of oxygenated volatile organic compounds fluxes from an alfalfa field before and after cutting, J. Geophys. Res.-Atmos., 107(D8), 4067, 10.1029/2001JD000594, 2002.

Webb, E. K., Pearman, G. I., and Leuning, R.: Correction of Flux Measurements for Density Effects Due to Heat and Water Vapor Transfer, Q. J. Roy. Meteor. Soc., 106, 85-100, 1980.

Wesely, M. L., Lenschow, D. H., and Denmead, O. T.: Flux Measurement Techniques, in: Global Tropospheric Chemistry, Report of the Workshop on Measurements of Surface Exchange and Flux Divergence of Chemical Species in the Global Atmosphere, edited by: Lenschow, D. H. and Wesely, M. L., Columbia Univ., New York, USA, 31-46, 1989.

Westberg, H., Lamb, B., Hafer, R., Hills, A., Shepson, P., and Vogel, C.: Measurement of isoprene fluxes at the PROPHET site, J. Geophys. Res.-Atmos., 106(D20), 24347-24358, 2001.

Wilczak, J. M., Oncley, S. P., and Stage, S. A.: Sonic anemometer tilt correction algorithms, Bound-Lay. Meteorol., 99, 127-150, 2001. 